\title{
New warning sensors to detect corrosion risk in reinforced concrete
}

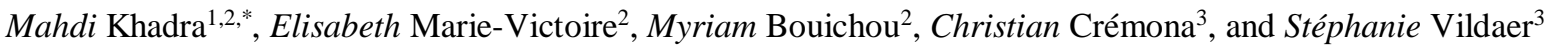 \\ ${ }^{1}$ Cercle des Partenaires du Patrimoine, 29 rue de Paris, 77420 Champs-sur-Marne, France \\ ${ }^{2}$ Laboratoire de Recherche des Monuments Historiques, 29 rue de Paris, 77420 Champs-sur-Marne, France \\ ${ }^{3}$ Bouygues Travaux Publics, Pôle Ingénierie Matériaux, 78114 Magny-les-Hameaux, France
}

\begin{abstract}
Corrosion is the most frequent but also the most deleterious deterioration mechanism affecting reinforced concrete. In addition to the economic impact of the repair works, for historical concrete structures, corrosion can generate irreversible losses of original material of great cultural value. If the usual non-destructive electrochemical methods have highlighted their efficiency in evaluating on-going corrosion activity, they also have pointed out their drawbacks for accurate extrapolation and prevention. To prevent the corrosion phenomenon, by detecting the penetration of aggressive agents, a new warning sensor system has been developed. The principle of the technique is to embed thin metallic sheets (called orphan blades) in the concrete cover, at different distances from the surface to the reinforcing bars. Then the corrosion of those very reactive orphan blades is followed during the propagation of the carbonation front and/or the penetration of chloride ions using stimulated infrared thermography. The corrosion of the sensors at different depths is indicative of the ingress speed of the front and can alert about the risk of corrosion of reinforcing bars in the concrete. The purpose of this study is to present this new technique and the first results obtained in the laboratory on corroded and non-corroded sensors.
\end{abstract}

\section{Introduction}

Nowadays, concrete has become the most used material in construction. However, concrete structures interact with the external environment which leads to their degradation over time [1]. Atmospheric $\mathrm{CO}_{2}$, in the presence of moisture, reacts with the main constituents of concrete [2]. This reaction, called carbonation, reduces the $\mathrm{pH}$ of the interstitial solution, which is initially basic (12 to 13 ) to a value lower than 9 , which initiates corrosion of the reinforcing bars [3]. In marine environments or in areas frequently exposed to de-icing salts, chloride ions can gradually penetrate concrete structures until they reach the reinforcement, and when the concentration of chloride ions exceeds a critical threshold, particularly active corrosion can develop $[3,5]$. Today, a large number of degraded concrete structures have reached an alarming threshold, and the economic issue related to the rehabilitation of this stock is estimated to 2 billion US dollars over the next 10 years only for the United States territory! [11]. Corrosion also causes major problems for conservation in reinforced concrete structures listed as historical monuments [4].

To evaluate the corrosion risk or even to assess active corrosion, the most used techniques are electrochemical methods, performed from the concrete surface $[5,6,7,8$, $9,10]$. But usually the measurements are local and depend on the environmental conditions: they can overor under-estimate the annual corrosion risk. For many years, the concrete department of LRMH has studied an adaptation of these techniques to improve the diagnosis accuracy by implementing continuous monitoring using sensors placed on the surface or embedded in the concrete structure $[12,13]$. These sensors are generally connected by wires to a data logger, remotely searchable by cell phone. This means that the installation is visible and that connection issues can appear on the long term. In addition most of these methods require a physical connection to the reinforcing bars.

To overcome these issues, but also to anticipate the corrosion before it reaches an irreversible state, a new warning system named "orphan blades" has been developed and patented by Bouygues Travaux Publics [14]. It is wireless, invisible from the surface, not based on electrochemical measurements and allows detection of the penetration of aggressive agents such as carbonation or chloride. In this paper this sensor system is explained and a laboratory study performed on reinforced concrete slabs, with sensors showing different states of corrosion, embedded at several depths is presented.

\section{New sensor systems}

\subsection{Principle of the technique}

The idea is to place ultra-thin metal sheets in the concrete cover and to monitor their corrosion during the

* Corresponding author: mahdi.khadra.ext@culture.gouv.fr 
propagation of $\mathrm{CO}_{2}$ or chloride ingress (Fig. 1) using stimulated infrared thermography. The gradual corrosion of the sheets (or orphan blades) embedded at different depths is indicative of the propagation of aggressive agents and of the risk of corrosion for the reinforcing bars.

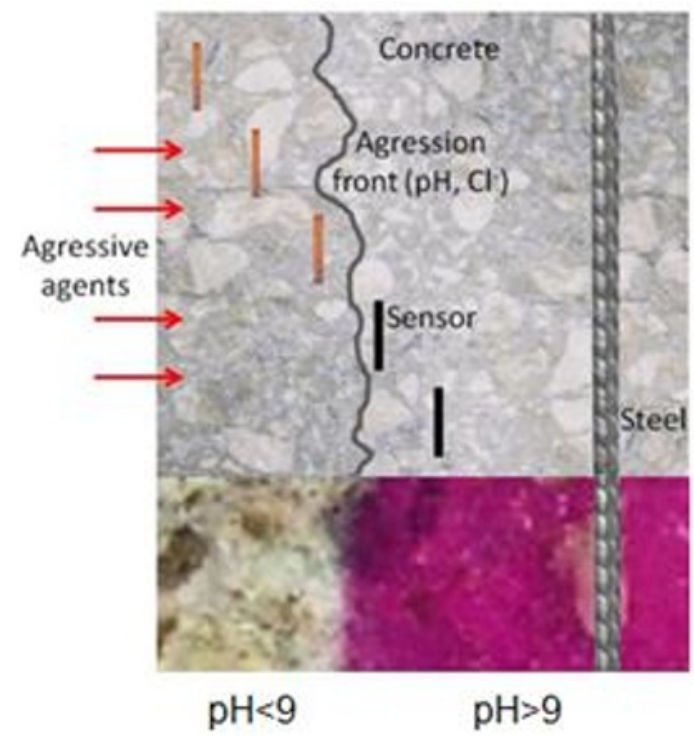

Fig. 1. Schematic principle of the technique

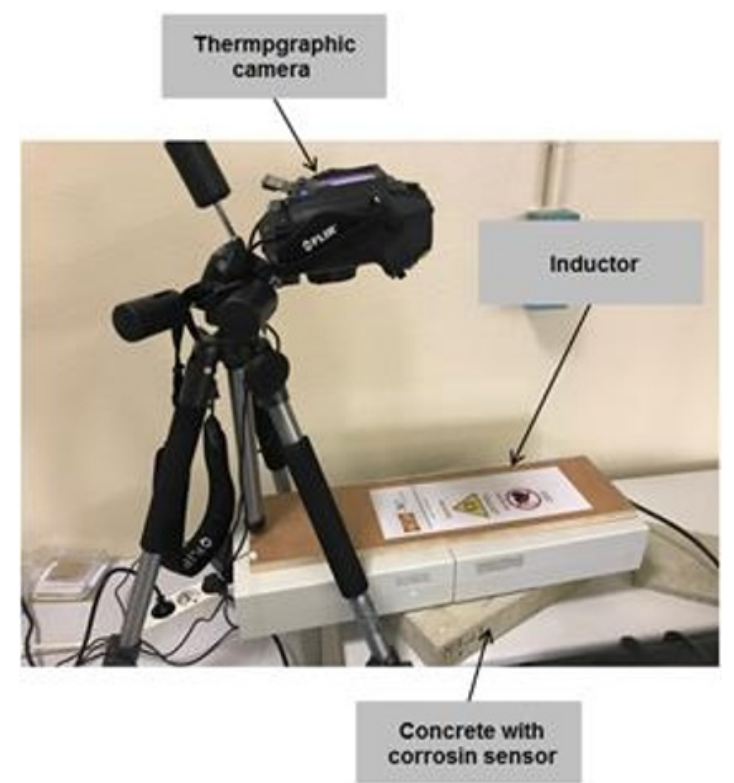

Fig. 2. Setting of the technique

In several industries, for nondestructive control of defect detection in conductive composites or metals, electromagnetic methods are widely used. Magnetic induction (Lenz's law) is one of the most used techniques. The currents induced by the coil of the inductor placed close to the metallic surface, heat the surface region. Then any surface defect disturbs locally these currents and induces local modification in the temperature of the surface.
In the idea of stimulating the orphan blades embedded in the concrete using magnetic induction, a specific inductor was developed. It uses an appropriate electrical power, which, associated with a suitable coil, generates an alternating magnetic field powerful enough to heat the metallic blades up to several centimeters into the concrete cover, by mobilizing electrons on their surface (eddy currents). The consequence is that sound metallic blades will be heated while corroded ones will behave differently. The rise of temperature of the sheets propagates to the surface and can be detected using a thermographic camera (Fig. 2).

\subsection{Sensor positioning}

To perform the most accurate measurement, sensors must be placed in the concrete cover parallel to the concrete surface in order to be parallel to the camera line of sight during the thermographic acquisition. The compliance of this criterion is fundamental but can be disturbed by the vibration of concrete during casting, which can modify the position or angle of orientation of the sensors. To solve this problem, a sensor support system was designed (Fig. 3). It is composed of two parts. The first part is a frame that keeps the sensor parallel to the concrete surface, and prevents any deformation. It is composed of a square slot, perpendicular to a rectangular rod that is dedicated to positioning the sensor vs the reinforcing bars. The second part, which is wedge-shaped, is intended to stabilize the system, to adjust the distance between the sensor and the reinforcing bars in the formwork, and therefore to adjust the desired depth of the sensor versus the surface. Thanks to the combination of the rod of part 1 and the wedge of part 2, the system can be attached to the reinforcing bar using a plastic clamp collar for which a central band in the rod was designed.

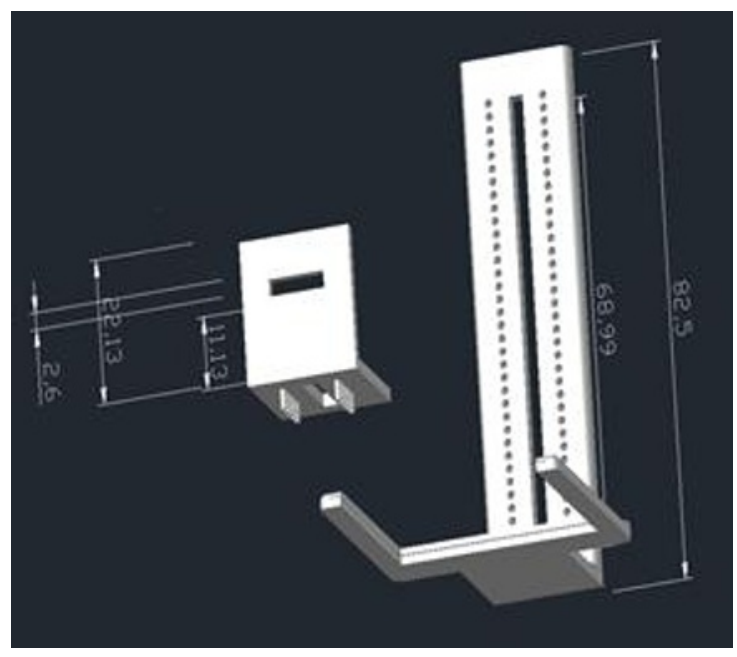

Fig. 3. Sensor support system. 
The whole support system was produced using 3D printing with a specific heat inert polymer.

\subsection{Data acquisition and treatment processes}

For the data acquisition, a T420 FLIR thermal camera, with a $0.1^{\circ} \mathrm{C}$ thermal sensitivity was used. The data was acquired using the ResearchIR MAX 4.0 software by connecting the camera to a computer (Fig. 4). The measurements were carried out according to a 7 step protocol.

- Step 1: Place the specimen to be tested under the thermal camera so that the lens of the camera is parallel to the surface of the sample. The camera is equipped with a laser pointer to focus on the centre of the sensor whose position is known in the slab.

- Step 2: Connect the camera to the computer equipped with the dedicated software and adjust the parameters, such as the emissivity $(\varepsilon=0.93$ for concrete), the distance between the camera and the specimen, and the ambient temperature.

- Step 3: Place the inductor on the surface of the specimen so that the centre of the coil of the inductor is placed on the centre of the sensor.

- Step 4: Turn on the inductor and heat for a preset time.

- Step 5: During heating, press the record button to record the video of the thermal response of the sensor.

- Step 6: At the end of the heating time, turn off the inductor and remove it from the surface of the specimen.

- Step 7: Follow the evolution of the thermal response on the computer until the total dispersion of the thermal signal on the surface of the sample; turn off recording and save the file for data processing.

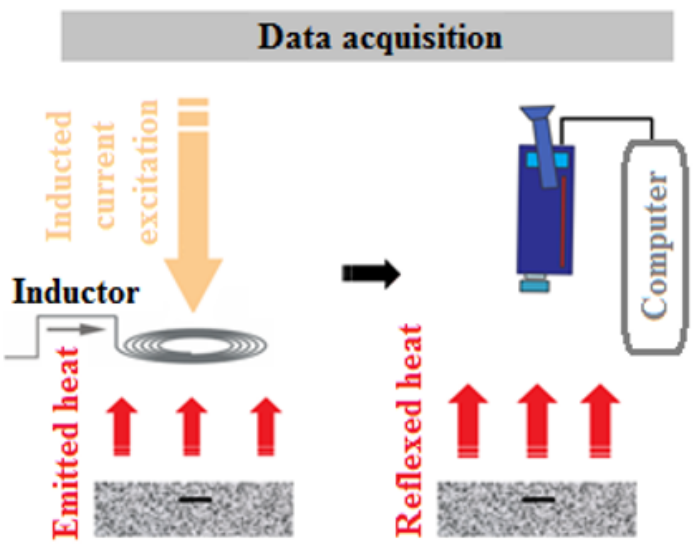

Fig. 4. Data acquisition processes

The first step in data processing is to extract the first thermal image appearing immediately at the end of the induction heating time (Fig. 5). The second step consists in framing the reflected area of the sensor on the concrete surface using the BOX tool provided by the software, and to follow the evolution of the thermal response on the diagonal line of the BOX (Fig. 6).
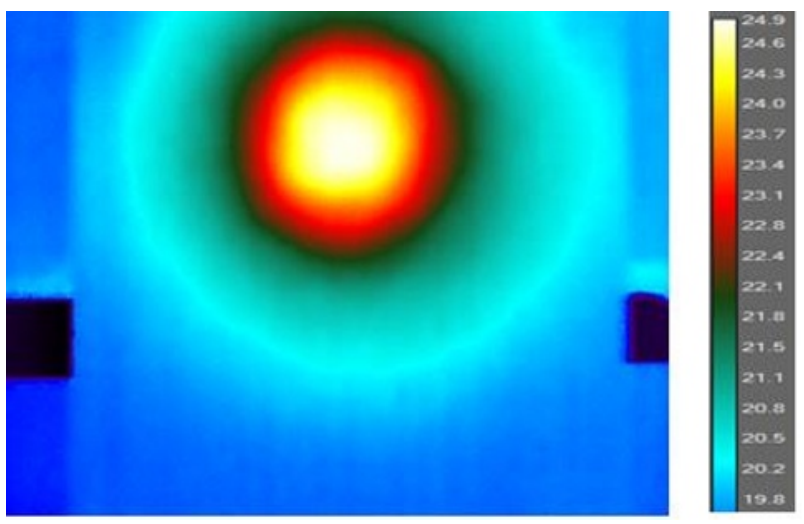

Fig. 5. Thermal apparent image in the infrared spectrum after heating.
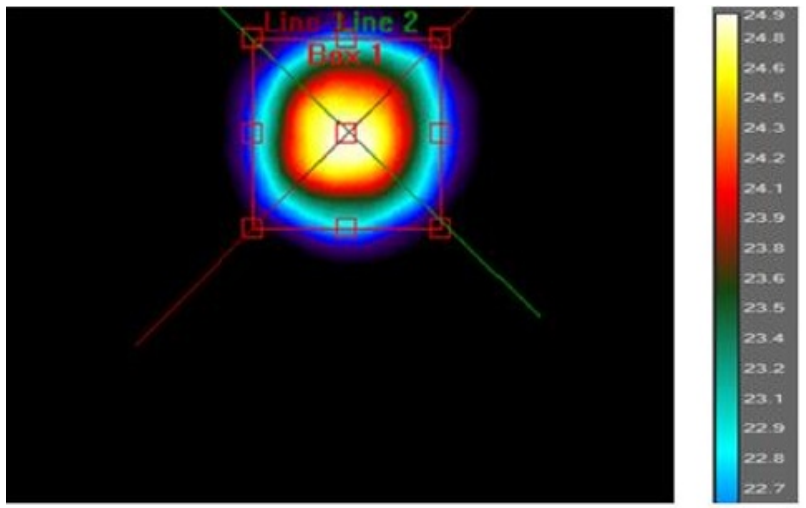

Fig. 6. Thermal apparent image in the infrared spectrum of the sensor area after heating.

The thermal responses are then represented as a regression of the maximal apparent temperature of the line versus time.

\section{Experimental program and results}

In order to evaluate the sensitivity of the technique regarding the corrosion state of the sensor, a series of tests was performed using corroded and non-corroded sensors placed into concrete at different depths.

\subsection{Artificial corrosion}

Prior to their introduction in the concrete the sensors were submitted to artificial ageing. They were first inserted in their polymer frame. Then a series of cycles of immersion (in the evening and overnight) in a hypochlorite solution with $2.6 \%(\mathrm{~m} / \mathrm{m})$ active chlorine, followed by drying (in the morning and the afternoon), was applied. To perform a preliminary characterization of the sensors after artificial corrosion, images in both the visible and infrared spectrum were taken for each sensor, after 6 days at room temperature (Fig. 7). 
Corrosion is visible to the naked eyes, but also on the IR images, the sound zones reflecting the radiation and therefore having a higher apparent temperature than the corroded parts.

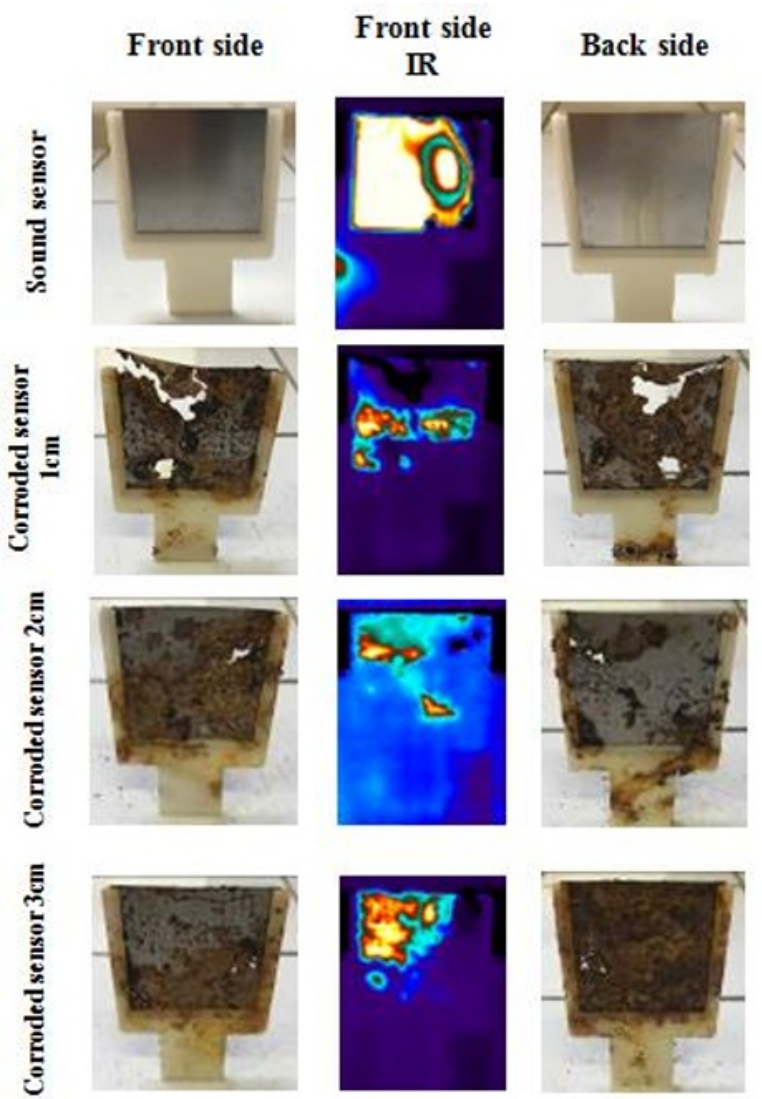

Fig. 7. Images of the sensors in visible and infrared spectrum.

\subsection{Sample preparation}

The concrete considered for this study was a mix of CEM I $52.5 \mathrm{~N} \mathrm{CP} 2\left(275 \mathrm{Kg} / \mathrm{m}^{3}\right)$, with a water to cement ratio of 0.74 and aggregates with a max diameter of $16 \mathrm{~mm}$. The slabs were cast in wooden moulds of $22 \times 17 \times 8 \mathrm{~cm}$. In each slab, only one sensor was fixed at the middle of the rebar before concrete casting, at a depth controlled thanks to the support system. Three depths were considered: $1 \mathrm{~cm}, 2 \mathrm{~cm}$ and $3 \mathrm{~cm}$. The formwork was filled in each case in two steps in order to optimize the vibration and the quality of the concrete around the sensors (Fig. 8). After casting, the slabs were stored for one month in an outside covered place in contact with atmospheric air.
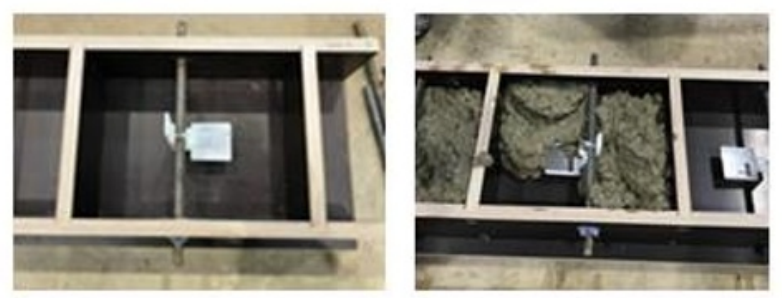

Fig. 8. Fixation of the sensor system to the rebar before concrete casting.

\subsection{Results and discussion}

Prior to the measurements, the slabs were moved to a room with controlled temperature for two days, in order to stabilize their initial temperature. Measurements were then carried out according to the protocol detailed in section 1.3.

Figure 9 shows the infrared images obtained on the slabs containing either sound or corroded sensors placed at $1 \mathrm{~cm}$ from the concrete surface, after 10 minutes of heating with a $25 \mathrm{KHz}$ induction frequency. In the table, two types of images are presented: those showing the thermal response from the entire surface detected by the camera and those obtained by focusing only on the sensors.

As can be seen, the intensity of the hot spot and the elevation of the apparent temperature are higher for the sound sensor than that of the corroded sensor.

The intensity of the apparent temperature can be quantified by extracting the maximal apparent temperature on the diagonal line of the BOX. When plotting the curve of these maximal apparent temperatures versus time, sound and corroded sensors can be clearly distinguished (Fig.10), so that this parameter can be considered as a quantitative indicator of corrosion.
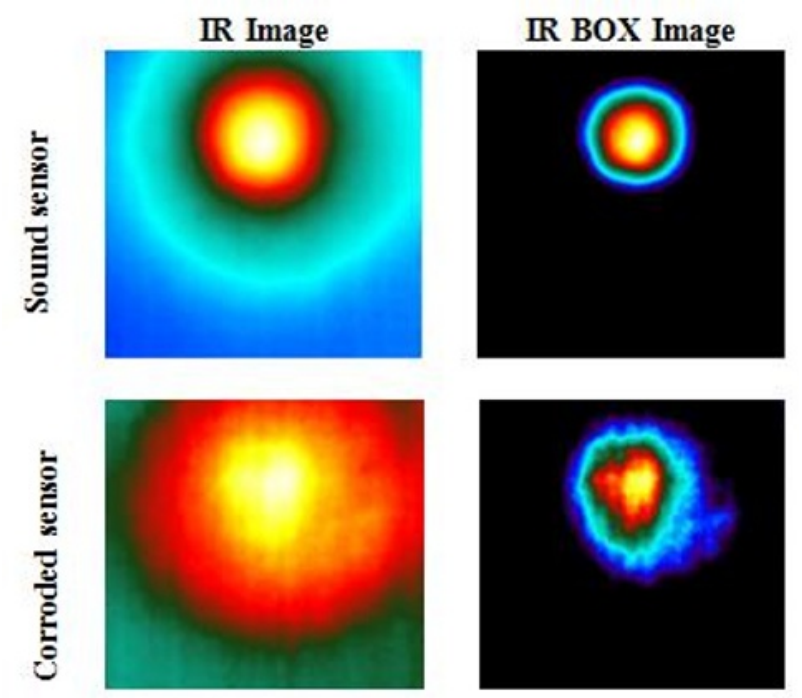

Fig. 9. Results obtained after 10 minutes of heating for the slabs containing sensors with a $1 \mathrm{~cm}$ concrete cover.

Figure 11 gathers the infrared images obtained on the slabs containing either sound or corroded sensors placed at $2 \mathrm{~cm}$ from the concrete surface, after 10 minutes of heating. As can be seen, the spot of the sound sensor is more defined and brighter than that of the corroded sensor. But the elevation of temperature of this sensor depth is lower than for the sensors placed at $1 \mathrm{~cm}$.

This is probably due to less efficient heating of the $2 \mathrm{~cm}$-depth sensors compared to those at $1 \mathrm{~cm}$-depth because the magnetic field decreases with depth, and because the thermal wave needs more time to appear on the surface of the slabs, and therefore part of the heat dissipates in the concrete by conduction. 


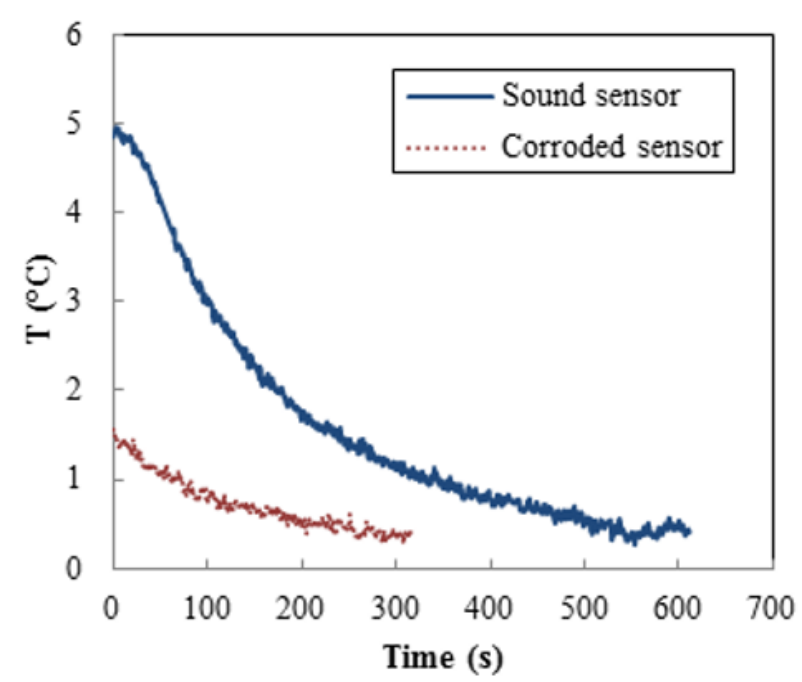

Fig. 10. Temperature versus time of the sensors with a $1 \mathrm{~cm}$ concrete cover after10 minutes of heating.

The qualitative observations were confirmed by the quantitative data as shown on figure 12, where the maximal apparent temperature is plotted versus time. It can also be noticed that for this higher concrete cover, sound and corroded concrete can still be quantitatively distinguished.
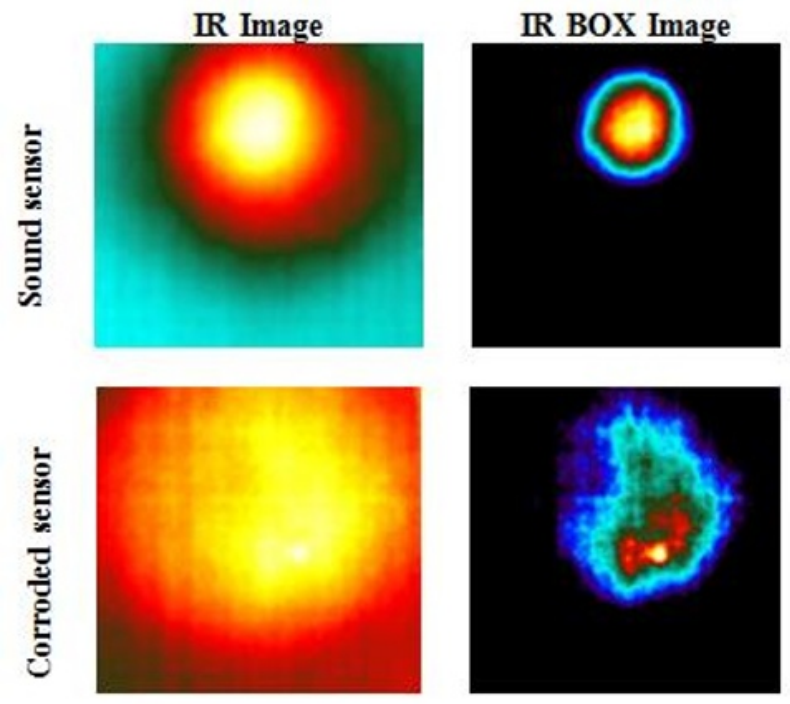

Fig. 11. Results obtained after 10 minutes of heating for the slabs containing sensors with a $2 \mathrm{~cm}$ concrete cover.

Figure 13 gathers the infrared images obtained for the sensors placed at $3 \mathrm{~cm}$ from the surface of the slabs. If sound and corroded sensors can be distinguished from the entire infrared images, it is more difficult from the BOX images. At the induction frequency used in this study, when the concrete cover increases, the heating of the sensor decreases and the thermal wave diffuses more in the concrete, and as a consequence, the apparent temperature at the concrete surface is reduced. Thus, the maximal temperature for the sound sensor placed at $3 \mathrm{~cm}$ is about $1.3^{\circ} \mathrm{C}$ (figure 14) when it is was $2.7^{\circ} \mathrm{C}$ for the sound sensor placed at $2 \mathrm{~cm}$ from the concrete surface (figure 12).

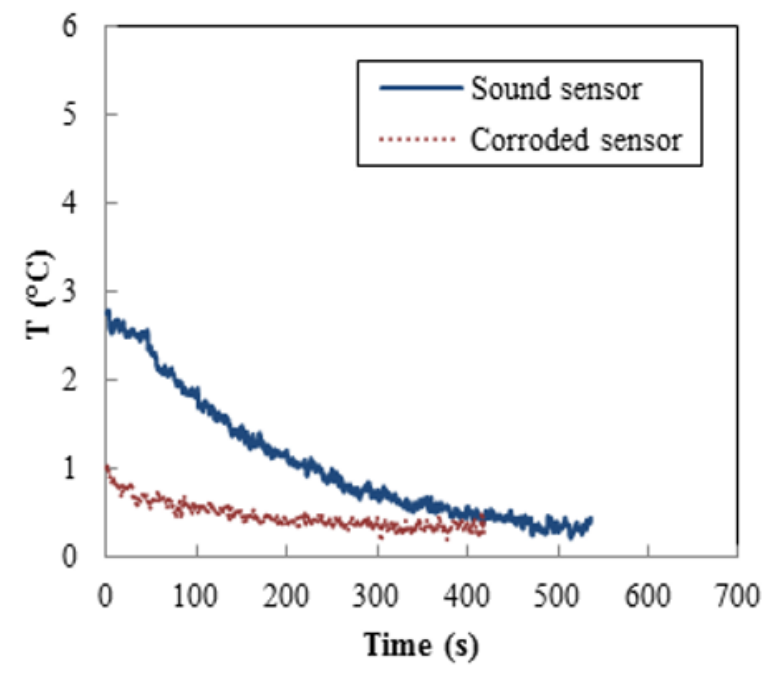

Fig. 12. Temperature versus time of the sensors with a $2 \mathrm{~cm}$ concrete cover after 10 minutes of heating.

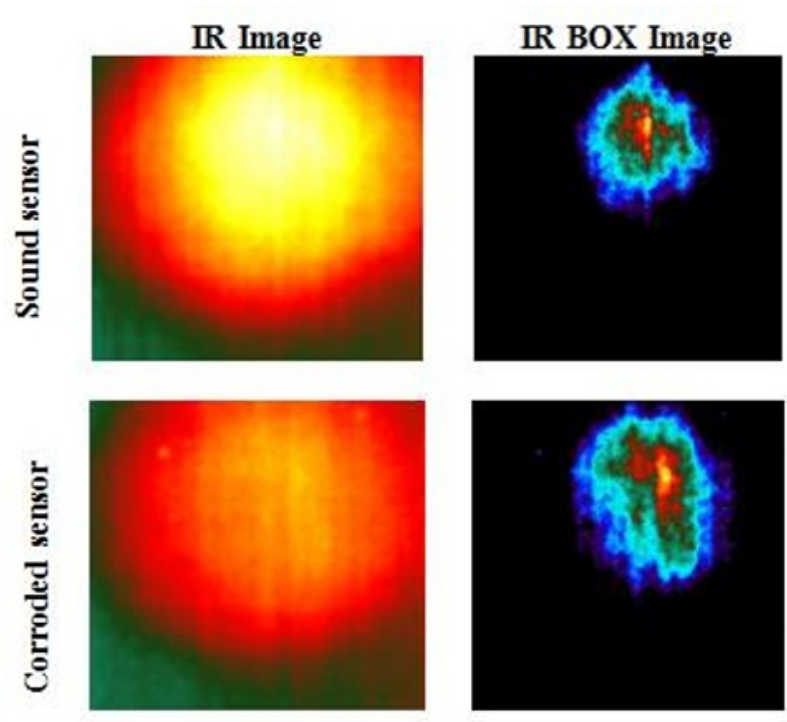

Fig. 13. Results obtained after 10 minutes of heating for the slabs containing sensors with a $3 \mathrm{~cm}$ concrete cover.

When comparing the curves of temperature versus time for the sound and corroded sensors with a $3 \mathrm{~cm}$ concrete cover, it can be observed that the maximal temperature difference is about $0.5^{\circ} \mathrm{C}$ (Fig. 14). This cannot be considered sufficient to distinguish sound and corroded sensors. 


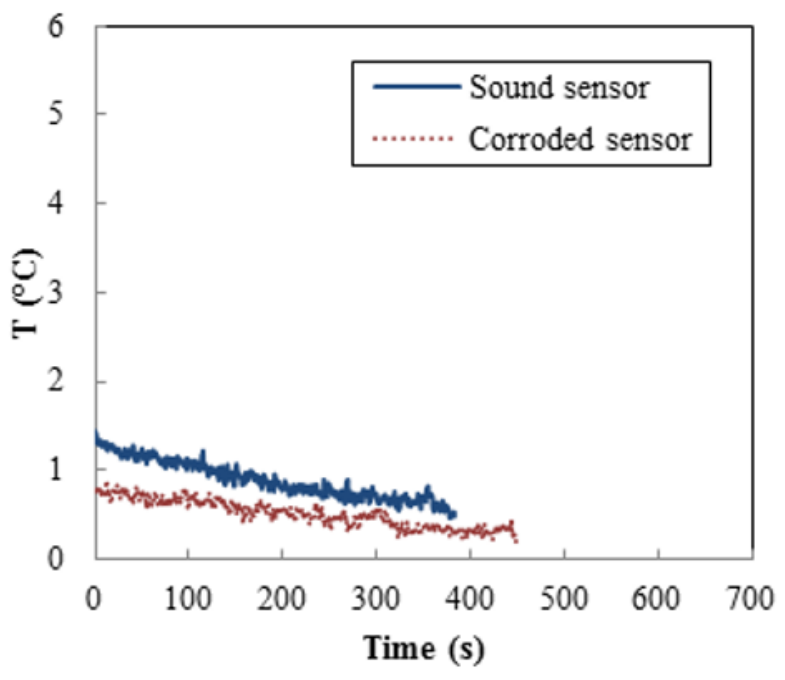

Fig. 14. Temperature versus time of the sensors with a $3 \mathrm{~cm}$ concrete cover after 10 minutes of heating.

\section{Conclusions and outlook}

A new warning system designed to anticipate corrosion of reinforcing bars in concrete was designed. The principle of this system is to place ultra-thin metal sheets, named orphan blades, at different depths in the concrete cover till the depth of the reinforcing bars and to monitor their corrosion versus time by stimulated infrared thermography. When aggressive agents such as carbonation or chlorides penetrate the concrete, the orphan blades will gradually corrode, their thermal signature will be modified, and therefore will warn about the progression of the risk of corrosion.

In this paper, a comparison between sound and corroded sensors embedded at three different depths in a concrete with a high water to cement ratio, susceptible to be more sensitive to corrosion was presented. The results show that whatever the concrete cover, sound and corroded sensors can be qualitatively distinguished, even when the sensors are not totally corroded. But dealing with quantitative analysis of the data, if the temperature differences between the two states (sound or corroded) were significant for the sensors embedded at 1 and $2 \mathrm{~cm}$ from the concrete surfaces, it was less evident for the sensors placed at $3 \mathrm{~cm}$. This is probably due to a less efficient induction heating when the depth increases and to the diffusion of the thermal wave into the concrete before it reaches the concrete surface.

As a conclusion, the orphan blades system appears to be a very promising technique to anticipate corrosion of reinforcing bars in concrete and constitutes an interesting alternative to the usual electrochemical measurements.

Further studies on sensors corroding directly in the concrete or on the influence of the heating time and environmental parameters are on-going.

A new inductor with a higher heating frequency $(33 \mathrm{KHz})$ is also under development. The first results obtained on sensors embedded at $3 \mathrm{~cm}$ and $4 \mathrm{~cm}$ from the concrete surface show that the maximal heating temperature is significantly higher than those obtained with the inductor used in this study. Therefore the technique could be applied to reinforced concrete with higher concrete covers.

\section{References}

1. J.P., Broomfield, Corrosion of steel in concrete: understanding, investigation and repair, ed. C. Hall, London: E \& FN SPON. 238 (1997)

2. M. Thiery, Modélisation de la carbonatation atmosphérique des matériaux cimentaires, Ecole Nationale des Ponts et Chaussées, PhD. Thesis (2005)

3. A. Bentur, S. Diamond, N.S. Berke, Steel corrosion in concrete: fundamentals and civil engineering practice. Modern concrete technology 6, ed. C. Hall, London : E \& FN SPON (1997)

4. E. Marie-Victoire, M. Bouichou, T. Congar, R. Blanchard, Concrete cultural heritage in France Inventory and state of conservation, In 4th ICCRRR : International Conference on Concrete Repair Rehabilitation and Retrofitting, October 5-7, 2015, Leipzig, Germany, 8p.

5. A. Dollet, G. Taché, Méthodes de diagnostic du béton armé, Anticorrosion et durabilité dans le bâtiment et le génie civil, S. Audisio and G. Béranger, pp. 659-668. Presses polyt. Et univ. Romandes ed (2010)

6. M. Raupach, Chloride-induced macrocell corrosion of steel in concrete-theoretical background and practical consequences. Construction and Building Materials, Vol. 10, 5, pp. 329-338 (1996)

7. M. Raupach, P. Schiessl, Monitoring system for the penetration of chlorides, carbonation and the corrosion risk for the reinforcement. Construction and Building Materials, Vol. 11, 4, pp. 207-214 (1997)

8. P. Schiessl, Corrosion measuring cell. Patent, US5015355 (1991)

9. J.-F. Lataste, C. Sirieix, D. Breysse, M. Frappa Electrical resistivity measurement applied to cracking assessment on reinforced concrete structure in civil engineering, NDT \& E International, Vol. 36, No. 6, pp. 383-394 (2003)

10. E. Marie-Victoire, M. Bouichou, H. Jourdan, Waterrepellents as alternative carbonation-induced corrosion treatments for reinforced concrete cultural heritage. In XIV DBMC: 14th international conference on durability of buildings materials and components, 29-31 May 2017, Ghent University, Belgium, p.399.

11. FHWA, Corrosion Costs and Preventive Strategies in the United States, FHWA-RD-01-156 (2002)

12. G. Villain, J.P. Balayssac, M. Fares, S.M. Sbartaï, J.F. Lataste, X. Dérobert, Comparaison de profils de taux de saturation obtenus par plusieurs méthodes 
non destructives électrique et électromagnétiques, actes Cong. Diagnobéton, Marrakech (MA), (2016)

13. M. Fares, Y. Fargier, G. Villain, X. Dérobert, O. Coffec, S. Palma-Lopes, Détermination du profil de teneur en eau dans le béton d'enrobage par inversion de mesures de permittivité au moyen de sondes capacitives, actes cong. Diagnobéton, Toulouse (2014)

14. Patents FR2955178A1, EP2521906B1, CA2786449C, WO2011083142A1, AU2011204622B2, MA33918B1, HRP20140053T1, Method for measuring corrosion in a concrete building, Bouygues Travaux Publics (2010-2014) 